\title{
МЕТОДИКА ОБРАБОТКИ ПОЛЯ ДЕТАЛЬНОЙ ГРАВИМЕТРИЧЕСКОЙ СЬЕМКИ В ЗОНЕ ВЛИЯНИЯ СОЛЕОТВАЛА
}

\author{
Г.В. ПРОСТОЛУПОВ \\ Горный институт УрО РАН, г. Пермь
}

\begin{abstract}
Аннотация: На подработанном участке солеразведочного рудника в районе техногенного озера вблизи солеотвала с интервалом в два года проведены детальные гравиметрические съемки для изучения геологической ситуации. В статье описаны параметры съемки, метод учета гравитационного влияния масс солеотвала, методика интерпретации поля, как измеренного, так и динамического. Сделаны выводы о значительном гравитационном влиянии масс солотвала и необходимости их учета, а также об эффективности сочетания классического метода обработки поля с мониторингом.
\end{abstract}

Ключевые слова: гравиметрическая съемка, солеотвал, аномалия, интерпретация гравитационного поля, мониторинг.

В 2016 и 2018 гг. в районе солеотвала на подработанной территории Соликамского рудоуправления проводились гравиметрические исследования. Цель работ - анализ геологической ситуации в районе техногенного озера. Площадь гравиметрической съемки 2.0×2.6 км. Среднеквадратическая погрешность определения аномалий Буге с учетом погрешности наблюденных значений силы тяжести, определения высот и плановых координат пунктов наблюдений в 2018 г. составила 0.025 мГал. Сеть пунктов наблюдений $100 \times 100$ м, поле измерено на 546 пунктах рядовой сети. Диапазон изменения значений поля в пределах участка составляет 2.15 мГал.

Вблизи участка работ, но за его пределами, на расстоянии около 100 м от границы участка расположен солеотвал высотой до 90 м, диаметр сечения в основании солеотвала 0.9 км.

\section{Предварительная обработка поля}

Было сделано предположение о возможном искажении массами солеотвала гравитационного поля в районе детальной гравиметрической съемки. Предварительные двумерные модели, рассчитанные в программе GModRa2D [4], показали, что влияния таких масс может колебаться от 0.1 до 0.2 мГал.

Плотность пород солеотвала при решении прямой задачи была взята согласно таб-

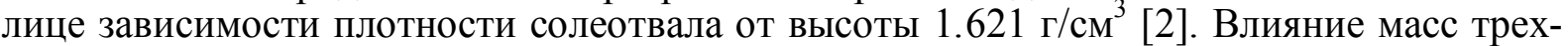
мерной модели солеотвала на пункты съемки были рассчитаны в программе Gravim [1]. Влияние масс солеотвала изменяется от 0.005 мГал в центре участка съемки до 0.22 мГал на границе участка, прилегающей к солеотвалам (рис. 1). Таким образом, модельные расчеты подтвердили что, при точности съемки 0.025 мГал, влияние солеотвала (до 0.22 мГал) является значительным.

Рассчитанный от модели солеоотвала гравитационный эффект был вычтен из наблюденного поля. Изменения поля после редукции заметны визуально, не говоря о трансформантах, еще более чувствительных к исходному полю.

\section{Интерпретация гравитационного поля, измеренного в 2018 г.}

Данные съемки обработаны в обновленной версии программы VECTOR [3], имеющей ряд преимуществ по сравнению с предыдущей версией. Это отсутствие ограничений по количеству точек, возможность сгущения матрицы векторов, позволяющее повысить качество разностных трансформант, особенно для анализа тонких слоев, расчет выходных данных в формате grd, снижающее искажение за счет отсутствия дополнительных интерполяций при построении карт и т.д.

Также на трехмерных диаграммах применено внедрение поверхностей (в данном случае отражающих горизонтов) в тело диаграммы, это позволило с высокой точностью видеть кривую пересечения поверхностей с вертикальным сечениями 3D диаграммы. При обработке в трехмерную трансформанту внедрены отражающие горизонты СМТ (соляно-мергельная толща), ПКС (покровная каменная соль) и подстилающая соль (рис. 2). В результате было отмечено, что на всех представленных вертикальных сечениях трехмерной трансформанты, отражающих пространственное плотностное 


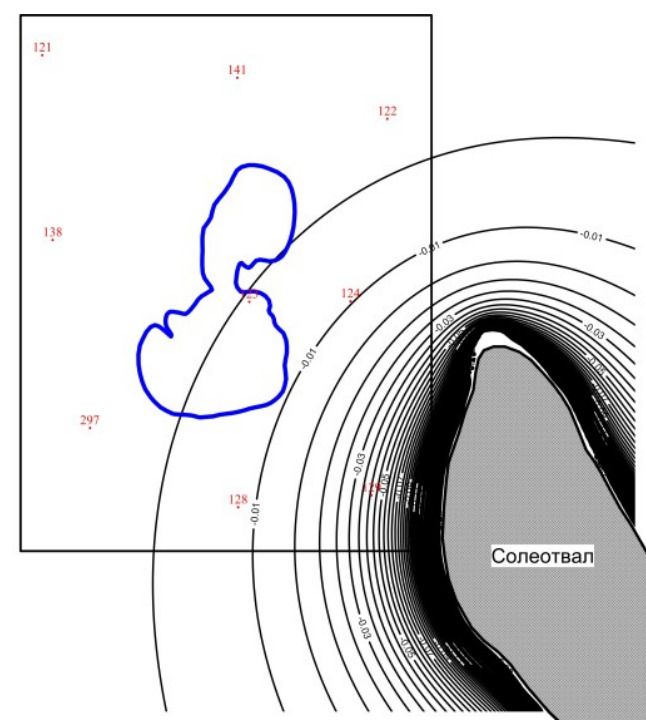

Рис. 1. Гравитационное влияние солеотвала на площади гравиметрической съемки строение породного массива, положение стратиграфических поверхностей (данные структурных карт), нанесенных на шкалу эффективных глубин, четко соответствует границам, где меняется рисунок аномалий, т.е. изменяется плотностное строение толщ.

Наряду с 3D трансформантами в системе VECTOR рассчитаны карты - двумерные разностные трансформанты, характеризующие плотностное строение между парой эффективных глубин. Так, в соответствии с геологическим строением, разрез подразделен на слои, с которыми рассчитаны разностные трансформанты: слой 0-130 м характеризует верхнюю часть разреза, 130 - 230 м соответствует глубинам соляно-мергельной толщи, а также покровной каменной соли, 230-320 м - водозащитной толще, 320-430 м - подстилающей соли, также дополнительно был создан «тонкий» слой в эффективном интервале 140-200 м, характеризующем соляномергельную толщу. В этом слое обнаружен эпицентр наиболее яркой отрицательной аномалии, которая распространилась также на выше- и нижележащие толщи. В плане эта аномалия расположена в южной части техногенного озера.

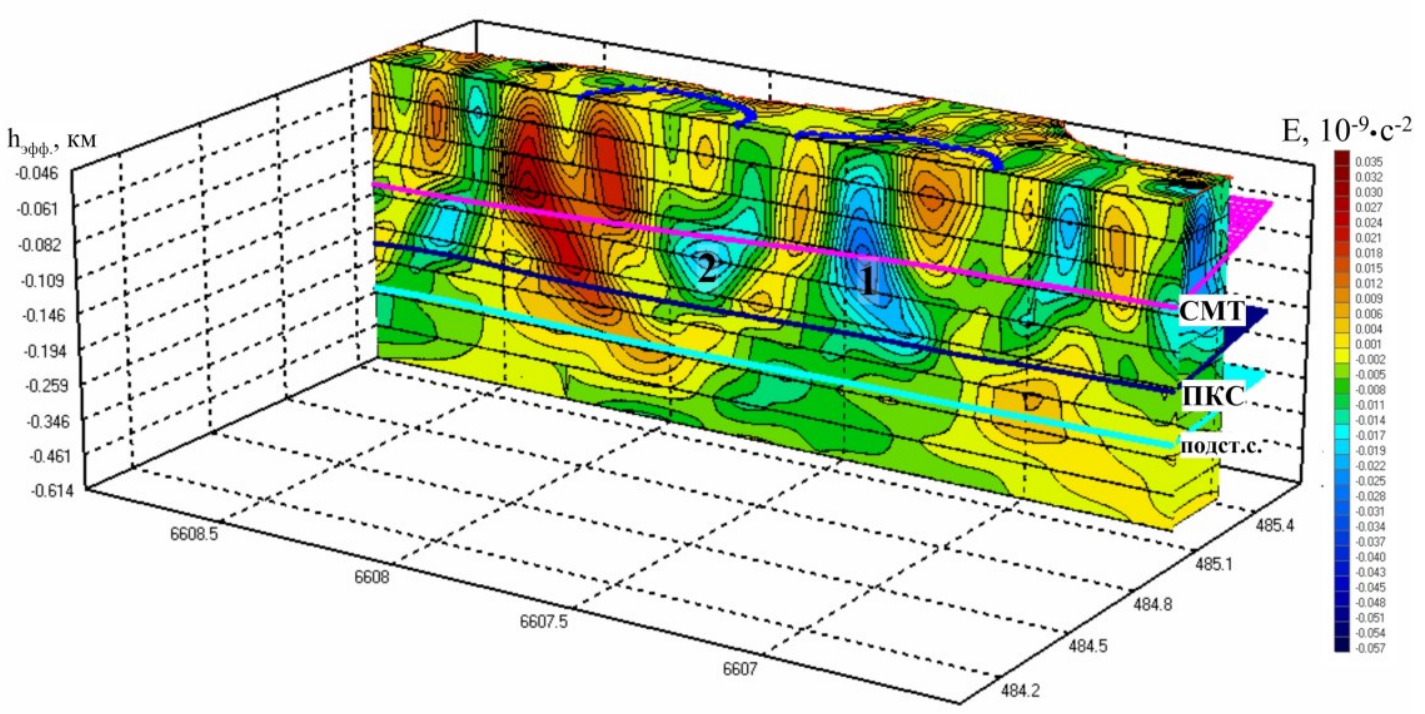

Рис. 2. Вертикальное сечение 3D-трансформанты разницы полей 2016-2018 гг.

B каждом слое при решении обратной задачи методом подбора в программе GModRa pacсчитана аномальная плотность в каждом слое. Разуплотнения достигают величин 0.12 г/ $\mathrm{cm}^{3}$.

\section{Мониторинг поля в период 2016-2018 гг.}

Наличие гравиметрических съемок разных лет позволяет выявить произошедшие за два года изменения в подработанном массиве. По такой же схеме было обработано и динамическое поле, результат вычитания поля, измеренного в 2018 г. и в 2016 г.

В целом обработка динамического поля показала, что в подработанной толще изучаемой территории, происходило неоднородное по площади и по разрезу разуплотнение пород. В динамическом поле наиболее интенсивная отрицательная аномалия 1 обнаружена в южной части техногенного озера (рис. 2), также как и при интерпретации наблюденного поля 2018 г.

Выявлена отрицательная аномалия и в северной части озера - разуплотнение 2. Так как на 3D диаграммах классического (нединамического) поля этой аномалии нет, можно сделать вывод об очень молодом времени ее происхождения и однозначно можно отнести к техногенным. 
Выводы. В данной работе обработка поля была разбита на два этапа - интерпретация поля, измеренного в 2018 году, характеризующая разуплотнения в настоящий момент и динамического поля как разницы полей, измеренных в 2016-2018 годах. Такой подход, совместной интерпретации классического метода обработки поля и мониторинга, позволил дополнить выявленные на первом этапе аномалии характеристиками их динамической изменчивости за последние два года, что в целом позволило подразделить аномалии на природные и техногенные. Подобный подход можно рекомендовать и при дальнейших исследованиях.

Можно сделать заключение о необходимости учета влияния солеотвалов, расположенных в районе гравиметрической съемки, с огромными массами пород, вносящими искажающий эффект в измеренное поле детальной съемки.

\title{
Работа выполнена при поддержке гранта РФФИ № 19-45-590011р_а.
}

\section{БИБЛИОГРАФИЧЕСКИЙ СПИСОК}

1. Бычков С.Г. Методы обработки и интерпретации гравиметрических наблюдений при решении задач нефтегазовой геологии / ГИ УрО РАН; отв. ред. В.И. Костицын. - Екатеринбург: УрО РАН, 2010. - 188 с.: ил.

2. Комаров Ю.А. Обоснование технологии высотного складирования пород-отходов при разработке калийных месторождений: дисс. ... к.т.н.; 25.00.22 / Комаров Юрий Альбертович. - СПб., 2016. - 162 с.: ил.

3. Тарантин М.В. Технологическое развитие системы «Вектор» // Стратегия и процессы освоения георесурсов: сб. науч. тр. Вып. 14 / ГИ УрО РАН. - Пермь, 2016. - С. 163-165.

4. Гравиметрическое моделирование разреза - «GModRa»: программа для ЭВМ: свидетельство о гос. регистрации № 2016661014 / Тарантин М.В., Простолупов Г.В.; заявитель и правообладатель ГИ УрО РАН - № 2016618439; заявл. 01.08.2016; зарегистрировано 28.09.2016; опубл. - 1 с.

\section{АЛГОРИТМ РАСЧЕТА РАДИАЛЬНОЙ СОСТАВЛЯЮЩЕЙ СИЛЫ ТЯЖЕСТИ}

\author{
В.В. ХОХЛОВА \\ Горный институт УрО РАН, г. Пермь
}

\begin{abstract}
Аннотация: В статье приведен краткий обзор существующих способов расчета радиальной составляющей силы тяжести. Представлен новый алгоритм вычисления радиальной составляющей, обусловленной влиянием сферического параллелепипеда. Предложенный алгоритм основан на применении кубатурных формул для вычисления тройного интеграла.

Ключевые слова: гравиразведка, сферический параллелепипед, радиальная составляющая, обработка полевых данных.

Традиционный подход к вычислению поправки за рельеф местности основывается на плоской границе «Земля-воздух», а топографические массы, как правило, аппроксимируются набором прямоугольных призм $[2,4,6]$. Такой подход привязывает нас к декартовой системе координат, в которой невозможно адекватно описать сферическую поверхность. Погрешность вычисления поля определяется детальностью аппроксимации геологических объектов геометрическими фигурами и погрешностью вычислительной процедуры от элементарной ячейки при превалирующем влиянии первой причины. Учитывая вышесказанное, представляется разумным переход из декартовой $\Sigma X Y Z$ системы координат в сферическую $\Sigma r \varphi \lambda$. Ряд исследователей предлагали разные 3D геометрические фигуры, содержащие элементы сферичности, для аппроксимации моделируемых геоплотностных неоднородностей: сферический диск [3], сферическая треугольная призма [7] сферический параллелепипед [8], сферический многогранник $[7,9,10]$. Таким образом, эти тела могут использоваться для создания «плотной упаковки» объектов в пределах сферической поверхности (или ее фрагмента). Выбор элемента аппроксимации должен осуществляться исходя из двух условий. С одной стороны, создание "плотной упаковки" при описании форм рельефа или геологический структур. С другой стороны, скорость и точность вычисления гравитационного поля от одного элемента.
\end{abstract}

